\title{
LAND-USE CHANGE DYNAMICS AND CLUSTER ANALYSIS OF AGRICULTURAL STRUCTURE IN THE ZULI RIVER BASIN IN RECENT 20 YEARS
}

\author{
Huiming Liu ${ }^{1,2}$, Fengmin $\mathrm{Li}^{1}$, Guojun Sun ${ }^{1, *}, \mathrm{Yu}$ Yang ${ }^{1}$ \\ 1 Key Laboratory of Arid and Grassland Agroecology, Lanzhou University, Lanzhou \\ Province, P.R. China 730000 \\ ${ }^{2}$ College of Resources Science \& Technology, Beijing Normal University, Beijing, P.R. China \\ 730000 \\ Corresponding author, Address: Key Laboratory of Arid and Grassland Agroecology, \\ Lanzhou University, Lanzhou 730000, Lanzhou Province, P. R. China, Tel: +86-931- \\ 8912842, Fax:+86-931-8912842,Email: sungj@lzu.edu.cn
}

Abstract: Based on the combined use of satellite remote sensing and geographical information systems(GIS), as well as field investigation, the land-use change dynamics and the interaction between these changes are analyzed in the Zuli River Basin located in semi-arid Loess Plateau China during the period of 1987-2005, which with typical farming-pastoral region feature of northern China. The land-use change of Zuli River Basin is divided into three successive phases. The results indicate that the area of grassland reduces $2.88 \%, 2.83 \%$ converting to farmland and $0.05 \%$ to urban and residential land from 1987-1993. Grassland reduces $0.25 \%, 0.19 \%$ converting to farmland and $0.06 \%$ to urban and residential land from 1993-2000. Farmland reduces $2.96 \%$, $2.94 \%$ converting to farmland and $0.02 \%$ to urban and residential land from 2000-2005, respectively. Moreover, the land use changes are also analyzed respectively in the cluster analysis. According to 10 natural and social indexes of 64 towns in Zuli River Basin, it is divided into three clusters and the landuse changes of these clusters are analyzed. We proposed different stratagems in three clusters of Zuli River Basin in this paper. These significant land use changes influenced by the policy of converting cropland to forestland and the increase of population occurring within the whole basin over the study period. The key factors of future development of Zuli River basin are the adjustment of structures between farmland and grassland, and the improvement of waterusing efficiency.

Please use the following format when citing this chapter:

Liu, H., Li, F., Sun, G. and Yang, Y., 2009, in IFIP International Federation for Information Processing, Volume 293, Computer and Computing Technologies in Agriculture II, Volume 1, eds. D. Li, Z. Chunjiang, (Boston: Springer), pp. 49-58. 
Keywords: Zuli River Basin; Farming-Pastoral Region; Land-use change; cluster analysis;

\section{INTRODUCTION}

For centuries, humans have been altering the earth's surface to produce food through agricultural activities. In the last few decades, conversion of grassland, grassland and forest into cropland and pasture has risen dramatically in the tropics (Houghton, 1994). This acceleration has concerned about the role of land use change in driving losses in many research fields.

3S technologies such as geographic information system (GIS), remote sensing (RS) and global positioning system (GPS), have given agricultural management unprecedented capacity to quantify farmland-grassland patterns and understand spatial heterogeneity of agriculture structure (Turner and Carpenter, 1998; Griffith et al., 2000). Many studies used spatial indices landscape patterns in agricultural systems and contrast them with natural systems (Gustafson, 1992; He et al., 2000). Understanding agricultural processes at a regional scale requires quantification of the spatial and temporal variations in farmland-grassland pattern, such as the area and structure of farmland-grassland. The dynamic of spatial and temporal patterns of agricultural landscape are critically important for crop management but difficult to measure or predict with current methods.

The Chinese Loess plateau is unique landscape in arid and semi-arid regions of the world. It has been described as one of the most serious soil erosion areas in the world with an estimated annual soil loss from cropland. There is a high risk of land degradation from improper management systems, overstocking, or opportunistic cultivation, limiting of the sustainable agriculture. It is a most important farming area in China, for there is plenty of arable land. It is important for sustainable agriculture development and ecosystem restoration to develop seeded grassland into crop-forage system (Li, 1999; Li et al., 2003).

Zuli river basin is located in Loess Plateau, Northwest China, which is in northern farming-pastoral transitional zone. In recent years, because of the development of Zuli river basin, population increases, urbanization process and The Conversion of Cropland to Forest and Grassland Project, the land use changes of Zuli river basin are the interaction results between human and nature. Based on the $3 \mathrm{~s}$ technology and survey data in the fields, we make detail analysis of the spatial and temporal changes of land use in Zuli river basin, which is the scientific support to the sustainable development of land and water resources in Zuli river basin. 


\section{STUDY AREA, DATA AND METHODS}

\subsection{Study Area}

The Zuli river basin draining to the upper catchments of the Yellow river, is located between longitude $104^{\circ} 12^{\prime}-105^{\circ} 33^{\prime} \mathrm{E}$ and $35^{\circ} 18^{\prime}-36^{\circ} 34^{\prime} \mathrm{N}$ in the northwest China, where it is well known as an important western part of the Chinese Loess Plateau. The area of the watershed is $10,653 \mathrm{~km}^{2}$. The elevations range from $1,400-2,000 \mathrm{~m}$. The mean annual air temperature is $8.8^{\circ} \mathrm{C}$ at the lowest (northern) end of the basin and decreases to $3.6^{\circ} \mathrm{C}$ at the highest (southern) end of the basin, and the mean annual precipitation is more than $500 \mathrm{~mm}$ at the southern end of the basin and gradually decreases northward to only $250 \mathrm{~mm}$ in the northern end (Zhao et al., 2003). More than $60 \%$ of the annual precipitation in Zuli river basin occurred in June to September, and $50 \%$ of the annual precipitation occurred in the rainstorm form. The land use types mainly included farmland, grassland, urban and residential land.

\subsection{Data}

\subsubsection{Land use/cover Data Set}

The 1987, 1993, 2000 datasets were from Land-sat5 (TM) images during the summer season in 1987, 1993, 2000, and the year 2005 dataset was obtained from the CBERS also in the summer of this year. All datasets are treated by accurate atmospheric-geometric correction. Both these two datasets were manually interpreted based on field investigation, DEM scaled at 1:50,000 and topographic maps scaled at 1:100,000 studying area. By giving a new attribute (patch type) to each polygon the land use map, combining polygon with the same patch type. The original 18 land use types were reclassified into 6 major land use/cover types: farmland, forest, grassland, urban and residential land, bottom land, desert land. The above procedures and statistic of all the vector data and grid data in this paper were performed using ArcGIS 9.0, ArcView GIS Version 3.2 (ESRI, USA) software and their Spatial Analysis module.

\subsubsection{Other Statistic Data}

Crop area, population and other statistics came from Bureau of Statistics of Dingxi and Huining Country. These bureaus are authorized units engaged 
in the professional surveying of local environment and statistics of social and economic development, so this data is reliable.

Tab 1.The 6 major land use/cover types and their meaning in Zuli river basin

\begin{tabular}{|c|c|c|}
\hline Patch ID & Land use types & Patch type meaning \\
\hline 2 & Forest & Arbor, shrubbery, sparse woods and tree nursery \\
\hline 3 & Grassland & $\begin{array}{l}\text { Grassland which coverage is more than } 5 \% \text { and land mixed rangeland } \\
\text { with the coverage of shrub canopies less than } 10 \%\end{array}$ \\
\hline 4 & Bottomland & $\begin{array}{l}\text { Land covered by natural water bodies or land with facilities for } \\
\text { irrigation and water reservation }\end{array}$ \\
\hline 5 & Urban and residential land & Including city, industry, traffic land and mine, and rural settlement \\
\hline 6 & Desert land & Desert, bare land, rock and gravel land \\
\hline 12 & Farmland & $\begin{array}{l}\text { All agricultural land, which including both paddy and non-irrigated } \\
\text { uplands }\end{array}$ \\
\hline
\end{tabular}

\subsection{Methods}

\subsubsection{Extract the boundary of Zuli river basin}

We using hydrological module in ArcGIS 9.0 to extract the boundary of Zuli river basin. The Zuli river basin extent does not exceed the administrative boundary; Take the grassland, forest and other land patches as the outer patches; Ensure the integrity of the outer patch (Li et al., 2006).

\subsubsection{The cluster analysis of social-economic data}

Cluster analysis is a scientific method for studying that things of one kind come together. Similar data can be grouped into the same cluster, and then each cluster needs only one rule to describe its characteristic, which is used to differ and classify the things according to their comparability. It is a process in which there is no one to guide them. So it is a non-supervising classifying and a tool to analyze data under no hypothesis (Neslihan, 2008).

The indices of sixty four towns in Zuli river basin are as followed: population quantity, per capita grain, farmland areas per person, total grain yield, reclamation ratio, population density, average slope, average precipitation, irrigation areas, irrigated farmland ratio. All of these ten natural and social indices have different dimension and order of magnitude. After excluding the affects of different dimension and order of magnitude, we make standardizing treatment for original data by the means of standard deviation. Sixty four towns in Zuli river basin are divided into three clusters of distinct characteristics. 


\section{RESULTS AND ANALYSIS}

\subsection{The landuse change in Zuli river basin}

As Figures 1 showed, the spatial and temporal land use changes in Zuli river basin is interpreted by TM and CBERS in the same method. Based on the particular investigation and the GPS data in Zuli river basin in 2005, we made the precision assessment of land use types in Zuli river basin, to present the whole precision of the land use monitoring process. As a result, the precisions of land use classification in 2000 and 2005 are $85.36 \%$ and $86.26 \%$. The precisions are settled for the next analysis and research.

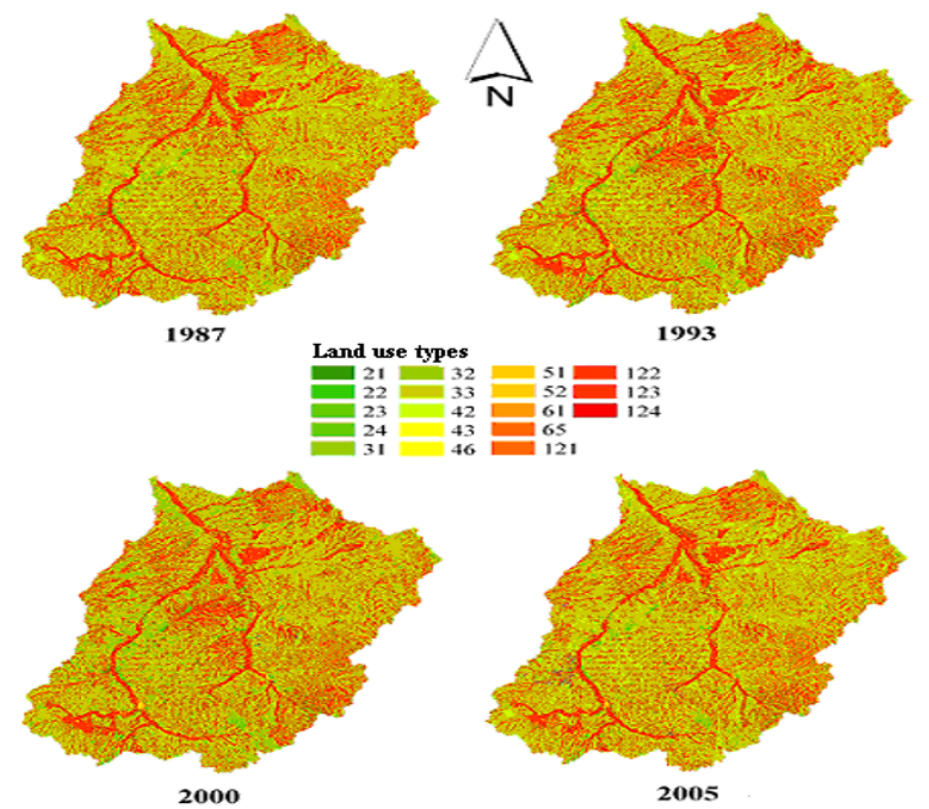

Fig1.Land use changes of Zuli River Basin from 1987 to 2005

21-forest land; 22-shrubbery; 23-open forest land; 24-other forest land; 31-high coverage grassland; 32moderate coverage grasslands; 33-low coverage grasslands; 42-lake; 43-reservoir; 46-beach land; 51urban land; 52-rural residential area; 61-sandy land; 65-bare ground; 121-mountainous farmland; 122-hilly farmland; 123 - plain farmland; $124->25^{\circ}$ slope farmland

As Figures 1 and Table 2 showed, farmland and grassland are the main land use/cover types in Zuli river basin in 1987, 1993, 2000, 2005.

Use the Spatial Analysis module in ArcView 3.2 to calculate the crosstabulation table, which was output as a transition matrix. The area of grassland in Zuli river basin decreased 2.88\% from 1987 to 1993, 
respectively $2.82 \%$ of grassland converted to farmland, $0.36 \%$ converted to urban and residential land. The area of grassland in Zuli river basin decreased $0.25 \%$ from $1987-1993$, respectively $0.18 \%$ of grassland converted to farmland, $0.07 \%$ to urban and residential land from 1993 to 2000. By contraries, the area of farmland in Zuli river basin decreased $2.96 \%$ from 2000 to 2005 , respectively $2.94 \%$ of farmland converted to grassland, and $0.02 \%$ to urban and residential land.

Tab 2.Land-use change of Zuli River Basin

\begin{tabular}{lcccccccc}
\hline \multirow{2}{*}{$\begin{array}{l}\text { Landuse } \\
\text { Types }\end{array}$} & \multicolumn{2}{c}{$\mathbf{1 9 8 7}$} & \multicolumn{2}{c}{1993} & \multicolumn{2}{c}{$\mathbf{2 0 0 0}$} & \multicolumn{2}{c}{$\mathbf{2 0 0 5}$} \\
\cline { 2 - 8 } & Area(km2) & Ratio(\%) & Area $\left(\mathrm{km}^{2}\right)$ & Ratio(\%) & Area $\left(\mathrm{km}^{2}\right)$ & Ratio(\%) & Area(km $\left.{ }^{2}\right)$ & Ratio(\%) \\
\hline Forest & 165.78 & $1.56 \%$ & 165.69 & $1.56 \%$ & 166.69 & $1.56 \%$ & 167.13 & $1.57 \%$ \\
Grassland & 5538.87 & $51.99 \%$ & 5232.22 & $49.11 \%$ & 5205.52 & $48.86 \%$ & 5518.63 & $51.80 \%$ \\
Bottomland & 10.45 & $0.10 \%$ & 10.51 & $0.10 \%$ & 10.54 & $0.10 \%$ & 10.15 & $0.10 \%$ \\
$\begin{array}{l}\text { Urban and } \\
\text { sidential land }\end{array}$ & 1024.26 & $9.61 \%$ & 1028.87 & $9.66 \%$ & 1035.74 & $9.72 \%$ & 1037.5 & $9.74 \%$ \\
$\begin{array}{l}\text { Desert land } \\
\text { Farmland }\end{array}$ & 20.46 & $0.19 \%$ & 19.77 & $0.19 \%$ & 19.77 & $0.19 \%$ & 19.61 & $0.18 \%$ \\
\hline
\end{tabular}

\subsection{The spatial land use changes of three clusters in Zuli river basin}

Based on the results of cluster-analysis by ten indices of natural and social characteristics, we divided the 64 towns of Zuli river basin into three ecological agriculture clusters (Fig.2). Cluster 3 is the irrigation section. It has the characteristics in land utilization of rather high cultivating ratio, town land utilization degree been rather low, the main producing area of grain and economic crops and better living and economic conditions in Zuli river basin. Cluster 2 is the dry farming agriculture distributed in gully region of Loess Plateau, and most farmland is the slop farmland with lower total grain yield, per capita yield and grain bearing capacity. Its mean precipitation amount is higher, so it has high potential to develop rainwater harvesting agriculture. Cluster 2 is the main attention points of rainwater harvesting agriculture which is flow losing of water and soil being great, and proportion of middle or low yield land being high. Cluster 1 is distributed in the plain field of Loess Plateau. It has a certain irrigated farmland, and low rate of efficient irrigation and poor irrigated condition, because of insufficient water resource. Cluster 1 is both irrigation and dry farming agriculture; the total grain yield and rural economic level are much lower than Cluster 3, but higher than Cluster 2. 


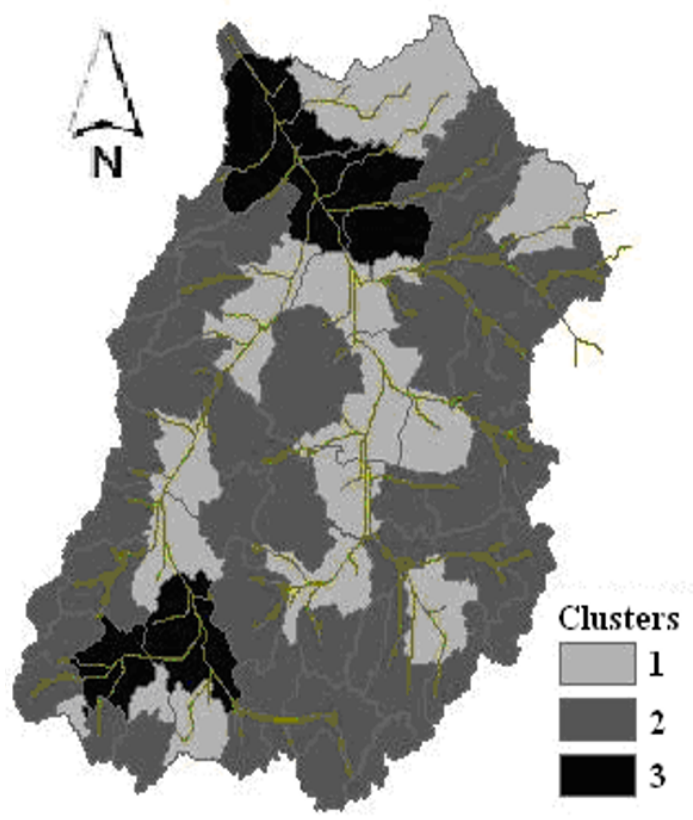

Fig 2. The three clusters of Zuli river basin

Using spatial analysis function of Arcview3.2, we overlaid the land-use maps of different temporal and different clusters, to calculate the crosstabulation table, which was output as a transition matrix, as Table $3,4,5$ showed.

Tab 3.Land-use change of cluster 1 in Zuli River

\begin{tabular}{lcccccccc}
\hline \multirow{2}{*}{ Landuse Types } & \multicolumn{2}{c}{$\mathbf{1 9 8 7}$} & \multicolumn{2}{c}{$\mathbf{1 9 9 3}$} & \multicolumn{2}{c}{$\mathbf{2 0 0 0}$} & \multicolumn{2}{c}{$\mathbf{2 0 0 5}$} \\
\cline { 2 - 8 } & Area(km2) & Ratio(\%) & Area $(\mathrm{km} 2)$ & Ratio(\%) & Area(km2) & Ratio(\%) & Area(km2) & Ratio(\%) \\
\hline Forest & 61.24 & $1.71 \%$ & 61.72 & $1.72 \%$ & 61.37 & $1.71 \%$ & 61.94 & $1.73 \%$ \\
Grassland & 1873.09 & $52.26 \%$ & 1791.13 & $49.90 \%$ & 1793.29 & $49.96 \%$ & 1862.99 & $51.91 \%$ \\
Bottomland & 1.76 & $0.05 \%$ & 1.76 & $0.05 \%$ & 1.8 & $0.05 \%$ & 1.76 & $0.05 \%$ \\
Urban and & 293.94 & $8.20 \%$ & 299.15 & $8.33 \%$ & 302.12 & $8.42 \%$ & 303.16 & $8.45 \%$ \\
residential land & 9.96 & $0.28 \%$ & 9.12 & $0.25 \%$ & 9.12 & $0.25 \%$ & 9.12 & $0.25 \%$ \\
Desert land & 1349.99 & $37.67 \%$ & 1426.3 & $39.74 \%$ & 1422.18 & $39.62 \%$ & 1350.91 & $37.64 \%$ \\
Farmland & & & & & & &
\end{tabular}

Cluster 1 in Zuli river basin: the land-use change is that farmland is continually increasing from 1987 to 2000, but decreasing from 2000 to 2005 . On the contrary, grassland is continually decreasing from 1987 to 2000, but increasing from 2000 to 2005 . 1987-2000 grassland area decreased $2.30 \%$, $1.95 \%$ to farm land, and $0.22 \%$ to urban and residential land; 2000-2005, farm land of Cluster 1 decreased $1.98 \%, 1.95 \%$ to grassland, and $0.03 \%$ for urban residents land. 
Tab 4.Land-use change of cluster 2 in Zuli River

\begin{tabular}{lcccccccc}
\hline \multirow{2}{*}{ Landuse Types } & \multicolumn{2}{c}{1987} & \multicolumn{2}{c}{1993} & \multicolumn{2}{c}{$\mathbf{2 0 0 0}$} & \multicolumn{2}{c}{$\mathbf{2 0 0 5}$} \\
\cline { 2 - 8 } Forest & Area $\left(\mathrm{km}^{2}\right)$ & Ratio(\%) & Area $\left(\mathrm{km}^{2}\right)$ & Ratio $(\%)$ & Area $\left(\mathrm{km}^{2}\right)$ & Ratio $(\%)$ & Area $\left(\mathrm{km}^{2}\right)$ & Ratio $(\%)$ \\
Grassland & 115.75 & $2.01 \%$ & 113.83 & $1.97 \%$ & 116.34 & $2.02 \%$ & 115.75 & $2.01 \%$ \\
Bottomland & 3127.63 & $54.23 \%$ & 2896.94 & $50.23 \%$ & 2878.16 & $49.91 \%$ & 3079.13 & $53.39 \%$ \\
Urban and residential land & 2.19 & $0.04 \%$ & 2.31 & $0.04 \%$ & 2.29 & $0.04 \%$ & 6.59 & $0.11 \%$ \\
Desert land & 530.05 & $9.19 \%$ & 549.29 & $9.52 \%$ & 553.81 & $9.60 \%$ & 555.43 & $9.63 \%$ \\
Farmland & 9.31 & $0.16 \%$ & 9.11 & $0.16 \%$ & 9.11 & $0.16 \%$ & 9.11 & $0.16 \%$ \\
\hline
\end{tabular}

Cluster 2 in Zuli river basin: the land-use change is that farmland is continually increasing from 1987 to 2000, but decreasing from 2000 to 2005 . On the contrary, grassland is continually decreasing from 1987 to 2000 , but increasing from 2000 to 2005 . 1987-2000 grassland area decreased $4.32 \%$, $3.91 \%$ to farm land, and $0.40 \%$ to urban and residential land; 2000-2005, farm land of Cluster 2 decreased 3.58\%, 3.48\% to grassland, and $0.03 \%$ for urban residents land.

Tab 5.Land-use change of cluster 3 in Zuli River Basin

\begin{tabular}{|c|c|c|c|c|c|c|c|c|}
\hline \multirow{2}{*}{ Landuse Types } & \multicolumn{2}{|c|}{1987} & \multicolumn{2}{|c|}{1993} & \multicolumn{2}{|c|}{2000} & \multicolumn{2}{|c|}{2005} \\
\hline & $\operatorname{Area}\left(\mathrm{km}^{2}\right)$ & Ratio(\%) & $\operatorname{Area}\left(\mathrm{km}^{2}\right)$ & Ratio(\%) & $\operatorname{Area}\left(\mathrm{km}^{2}\right)$ & Ratio(\%) & $\operatorname{Area}\left(\mathrm{km}^{2}\right)$ & Ratio(\%) \\
\hline Forest & 12.24 & $0.96 \%$ & 11.31 & $0.89 \%$ & 12.41 & $0.97 \%$ & 12.24 & $0.96 \%$ \\
\hline Grassland & 586.85 & $46.05 \%$ & 583.59 & $45.79 \%$ & 579.65 & $45.48 \%$ & 575.2 & $45.13 \%$ \\
\hline Bottomland & 0.09 & $0.01 \%$ & 0 & $0.00 \%$ & 0 & $0.00 \%$ & 0 & $0.00 \%$ \\
\hline Urban and residential land & 144.79 & $11.36 \%$ & 147.14 & $11.55 \%$ & 149.23 & $11.71 \%$ & 150.03 & $11.77 \%$ \\
\hline Desert land & 1.38 & $0.11 \%$ & 1.53 & $0.12 \%$ & 1.53 & $0.12 \%$ & 1.38 & $0.11 \%$ \\
\hline Farmland & 529.1 & $41.51 \%$ & 530.45 & $41.62 \%$ & 531.21 & $41.68 \%$ & 535.69 & $42.03 \%$ \\
\hline
\end{tabular}

Cluster 3 in Zuli river basin: the farmland continues to increase, the grass area from 1987 to 2000 reduced continually. From 1987 to 2005, the grass area reduces $0.92 \%$, respectively, $0.40 \%$ to urban and residential land; $0.52 \%$ to farm land.

\section{DISCUSSION}

Zuli river basin in the administrative regionalization belongs to Dingxi and Huining County in Gansu Province. The economic level of Dingxi and Huining Country is relatively backward. Along with some human factors, such as the population increase and agricultural reclamation activity, the farmland continued to increase, and grassland continued to decrease from 1987 to 2000 in Zuli river basin. After the Policy of Converting Farmland to Forest is carried out after October 1999, the farmland area reduced obviously. Up to 2005, it basically approached to the number of farmland area in 1987.

The land use changes of three clusters in Zuli river basin are also obvious. The trends of land use changes are generally in the same in both cluster 1 
and cluster 2, and they are consistent with the whole land use changes of Zuli river basin. However, cluster 3 has the different trends of land use changes. The farmland in cluster 3 is mainly irrigated. The grassland continued to reduce, but the reduction rate is much lower. The farmland continued to increase, and the rate is also low. It is the producing areas of food and economic crops and rural economy developed section in Zuli river basin, which is distributed in flat area, with agricultural irrigation and little area of returning land for farming to forestry. Cluster 2 is distributed in gully region of loess plateau, which primarily depended on rain-feed agriculture and farmland by slope farming. Total yields of grain and per capita grain are in the lowest level in Zuli river basin. The rate of converting grassland to farmland is the biggest in the whole basin. Because of the Returning Land from Farming to Forest Policy, the areas of grassland in cluster 2 increased slightly after 2000, but not reach the areas of grassland in 1987. Cluster 1 is mainly distributed in plain areas, and has a certain irrigated farmland. Because of the insufficient water resource and poor irrigated condition, growing population has added very pressure to agricultural production, Agricultural production of Cluster 1 has both dry agriculture and irrigation farming, and being of middle level among the three clusters in Zuli river basin. Total yields of grain and per capita grain are in the middle level.

We investigated the present land use situation from more than two hundred households in Zuli river basin, and over 94\% of them are in support of Conversion of Cropland to Forest and Grassland Project and restoration of eco-environment in Loess Plateau. During the implementation of Conversion of Cropland to Forest and Grassland Project, the government provides a certain amount of grain and subsidy. $56 \%$ of the investigated households express that if the national subsidy is stopped, they would continue to cultivate on the slope farmland which has been already returned to the grassland. These households are mostly distributed in gully region of Loess Plateau, and depended on slope farmland. They belong to the towns of cluster 1 and cluster 2 which is also the main land use change area in the cluster analysis in this paper. The total yields, per capital of grain and grain bearing capacity are much lower.

To achieve social overall development in Zuli river basin, it is a significant study to accomplish The project of Conversion of Cropland to Forest and Grassland, as well as to make a breakthrough on regulation of agriculture structure and rural economic structure, to harmonize relations between the project and regulation, to advance ecological environments and improve rural economic development in the whole basin. Based on the above principles, we divided the whole basin into three clusters:

(1) Cluster 1 is the mainly land use change area, and its cultivation is mainly distributed in the slope farmland. It is mostly affected by the Conversion of Cropland to Forest and Grassland Project. This cluster should 
adjust of structures between farmland and grassland, and the improvement of water-using efficiency.

(2) Cluster 2 is also the mainly land use change area, and its annual precipitation is the highest in three cluster. It is the key cluster to develop rainwater harvesting agriculture and has high potential of water resource to develop high-efficiency agriculture.

(3) Cluster 3 is the irrigated agriculture area which is little affected by the Conversion of Cropland to Forest and Grassland Project. Its annual precipitation is much lower, so Cluster 3 has no enough precipitation to develop rainwater harvesting agriculture. Developing high efficient irrigated cultivation is the key stratagem in this cluster.

\section{ACKNOWLEDGEMENTS}

Financial support for this work was provided by the ISTCP for National S keletal System for Agricultural Project Crops Mapping in China (2006D FA31070).

\section{REFERENCES}

E. J. Gustafson, and G. R. Parker. Relationships between land cover proportion and indices of landscape spatial pattern, Landscape Ecology, 1992(7): 101-110.

H. S. He, B. E. DeZonia, and D. J. Mladenoff. An aggregation index (AI) to quantify spatial patterns of landscapes, Landscape Ecology, 2000(15): 591-601.

J. A. Griffith, E. A. Martinko, and K. P. Price. Landscape structure analysis of Kansas at three scales, Landscape and Urban Planning, 2000(52): 45-61.

Li Fengmin, Xu Jinzhang, Sun Guojun. Restoration of degraded ecosystems and development of water-harvesting ecological agriculture in the semi-arid Loess Plateau of China. Acta Ecological Sinica, 2003, 23(9): 1901-1909.

Li Fenmin, Wang Jin. The Rain Water Harvesting Technology Approach For Dryland Agriculture in Semi-Arid Loess Plateau of China. Acta Ecological Sinica, 1999, 19(2): 259-264.

Li Xiaoyu, Xiao Duning, He Xingyuan, et al. Dynamics of typical agricultural landscape and its relationship with water resource in inland Shiyang river watershed, Gansu Province, Northwest China. Environmental Monitoring and Assessment, 2006(36): 325-335.

M. Turner, and S. Carpenter. At last: A journal devoted to ecosystems, Ecosystems, 1998(11): $1-4$.

Neslihan Toyran, Feride Severcan, Mete Severcan, et al. Effects of selenium supplementation on rat heart apex and right ventricle myocardia by using FTIR spectroscopy: A cluster analysis and neural network approach. Food Chemistry, 2008, 110(3): 590-597.

R. A. Houghton. The Worldwide extent of land-use change, Bioscience, 1994, 44: 305-313.

Zhao Chuanyan, Nan Zhongren, Feng Zhaodong. GIS-assisted spatially distributed modeling of the potential evapotranspirationin semi-arid climate of the Chinese Loess Plateau. Journal of Arid Environment, 2004(58): 387-403. 